\title{
Descriptive Cross-Sectional Study on Acanthamoeba - Associated Pseudomonas Species at Kenyatta National Hospital Intensive Care Unit
}

\section{Zipporah W. Macharia}

University of Nairobi

Marianne W. Mureithi

University of Nairobi

Magdalene W. Mburugu

University of Nairobi

Wilfred Gitau

University of Nairobi

Moses M. Masika

University of Nairobi

Kariuki Njaanake ( $\boldsymbol{\sigma}$ kn@uonbi.ac.ke)

University of Nairobi

\section{Research Article}

Keywords: Free-living Amoeba, Acanthamoeba Species, Infection Control, Nosocomial Infections, Antimicrobial Resistance

Posted Date: March 1st, 2021

DOI: https://doi.org/10.21203/rs.3.rs-208683/v1

License: (c) (1) This work is licensed under a Creative Commons Attribution 4.0 International License. Read Full License 


\section{Abstract \\ Background}

Free-living amoeba (FLA) such as Acanthamoeba spp. are ubiquitous protozoa that graze on microorganisms such as bacteria, viruses and algae. However, amoebic resistant microorganisms (ARM) such as Pseudomonas spp. evade being killed by amoeba thus multiplying within the free-living amoeba. Free-living amoeba may therefore enhance transmission of Pseudomonas spp. across hospital environments thus contributing to the burden of nosocomial infections and spread of antimicrobial resistance. In Kenya, nosocomial Pseudomonas spp. infections present a major health challenge but the role of free-living amoeba such as Acanthamoeba spp. in transmission of these infections has so far not been assessed. This study aimed at the isolation of Acanthamoeba spp. from various surfaces and equipment and molecular detection of the Acanthamoeba-associated Pseudomonas spp.

\section{Methods}

This was a descriptive cross-sectional study in which 153 swabs in duplicate (306) were collected from selected surfaces and equipment. Acanthamoeba spp. cultures were performed on one batch of 153 swabs and bacterial cultures on the other batch of 153 swabs. Polymerase chain reaction (PCR) was performed to detect Pseudomonas sp. genomic deoxyribonucleic acid (DNA) within Acanthamoeba spp. isolates.

\section{Results}

The proportion of swabs that had Acanthamoeba spp. isolates was $93.5 \%(\mathrm{n}=153)$ while that of bacterial isolates was $82.4 \%(n=153)$. Of 168 bacterial isolates obtained, $10.7 \%$ was Pseudomonas spp. Acanthamoeba spp. subcultures were done on $62.7 \%(n=153)$ primary Acanthamoeba spp. isolates. Only $22.9 \%(n=96)$ of the Acanthamoeba spp. subcultures were successful. Pseudomonas sp. genomic DNA was detected in $45.5 \%(n=22)$ of all positive Acanthamoeba spp. subcultures using PCR.

\section{Conclusion}

Pseudomonas sp., an ARM, exists within Acanthamoeba spp. on various surfaces and equipment at $\mathrm{KNH}$ ICU. This suggests a possible role of Acanthamoeba spp. in Acanthamoeba- ARM associated nosocomial infections transmission and in spread of antimicrobial resistant genes across microorganisms in hospitals.

\section{Introduction}


Free living amoeba (FLA) such as Acanthamoeba spp. are ubiquitous protozoa that have been isolated in virtually all environments in nature and in anthropogenic milieu globally (Saeed et al., 2012; Chow and Glaser, 2014; Lakhundi, Siddiqui and Khan, 2015; Fabres et al., 2016; Rubenina et al., 2017). FLA phagocytose microorganisms from the environment such as bacteria, algae, fungi, protozoa and particles rich in energy for nutrition (Gimenez et al., 2011; Aç et al., 2013; Ovrutsky et al., 2013; Cervero-Aragó et al., 2015; Fabres et al., 2016).

However, some amoeba resistant microorganisms (ARMs) resist amoebic killing and proliferate within FLA following phagocytosis. These ARMs are released into the environment as free pathogens or in vesicles (Greub and Raoult, 2004; Barnard, 2015). Common human pathogenic ARMs include bacteria of the families Pseudomonaceae, Enterobacteriaceae, Mycobacteraceae and Vibrionaceae, and viruses (Greub and Raoult, 2004; Aç et al., 2013; Ovrutsky et al., 2013; Guimaraes et al., 2016).

FLA hosting ARMs act as concealed niches of microorganisms that propagate continuous circulation of pathogens and drug resistant genes across hosts and the environment (da Rocha-Azevedo, Tanowitz and Marciano-Cabral, 2009; Lamrabet et al., 2012; Altayyar et al., 2016; Fabres et al., 2016). Other effects of FLA- ARMs interactions include ARMs enhanced pathogenicity and virulence, ARMs training against macrophages, protection against harsh conditions and contribution to nosocomial infections burden despite stringent infection control measures (Horn, 2001; Khan and Siddiqui, 2014; Fabres et al., 2016; Balczun and Scheid, 2017; Rubenina et al., 2017).

The most common FLA linked to human disease is Acanthamoeba spp. (Guimaraes et al., 2016; Balczun and Scheid, 2017). It has been isolated from water, soil, dust, hospital environment and equipment such as dental units, used contact lenses, ventilators, dialysis units and ocular wash stations (Moon et al. 2008; Marciano-Cabral \& Cabral 2003;Jeong \& Yu 2005; Lass et al. 2014; Teixeira et al. 2009). Isolates of Acanthamoeba spp. have also been obtained from infected human specimens such as the lungs, brain tissues, corneal biopsies, cerebral spinal fluid and genitourinary tracts (Szénási et al., 1998; Jeong and Yu, 2005; Dendana et al., 2008; Siddiqui and Khan, 2012).

Acanthamoeba sp. exists as trophozoites and cysts with the former being the pathogenic stage which is metabolically active and motile. The cyst is the dormant stage and it is formed at the end of growth cycle or in harsh environmental conditions. Cysts survive desiccation, temperature changes, disinfectants, biocides, radiation, chlorination, $\mathrm{pH}$ changes, antibiotics, osmotic pressure variations and reduced nutrients (Marciano-Cabral and Cabral, 2003a; Siripanth and Med, 2005; da Rocha-Azevedo, Tanowitz and Marciano-Cabral, 2009; Teixeira et al., 2009; Booton et al., 2010; Bertelli and Greub, 2012; Clarke et al., 2012; Cervero-Aragó et al., 2015; Chomicz et al., 2015; Hsueh and Gibson, 2015). They also act as reservoirs and sources of infections due to their ability to survive for several years in the environment (Marciano-Cabral and Cabral, 2003b; Essa et al., 2016). Both trophozoites and cysts have been isolated from the environment as well as from infected human tissues (Khan, 2003; da Rocha-Azevedo, Tanowitz and Marciano-Cabral, 2009). 
Acanthamoeba spp. existence in hospital environment pose an explicit risk of expedient infections to the immunocompromised patients such as granulomatous amoebic encephalitis (GAE), sinusitis and skin lesions (Barnard, 2015; Shokri et al., 2016; Taravaud, Loiseau and Pomel, 2017; Souza, 2018). Amoebic keratitis is manifested among the immunocompetent individuals commonly in the contact lens users, patients with corneal injury and those living in places with inadequate water supply (Chappell et al., 2001; Khan, 2003; Booton et al., 2010; Clarke et al., 2012; Muchesa et al., 2014). Besides, Acanthamoeba spp. have been associated with more than 100 species of pathogenic bacteria which may be transmitted to humans and higher animals (Douesnard-Malo and Daigle, 2011; Gryseels et al., 2012; Aç et al., 2013; Fabres et al., 2016). Pseudomonas sp., a known ARM with high antibiotic and disinfectants resistance, increased virulence is also an etiologic agent of nosocomial infections (Lim and Webb, 2005).

The ubiquity of Pseudomonas sp. allows for its vast spread to patients from diverse sources including air, food, water, visitors, linen, contaminated medical personnel, contaminated surfaces and equipment such as catheters and ventilators which readily predisposes patients to nosocomial infections (Davane et al., 2014). Pseudomonas has been isolated from bacterial cultures as an etiologic agent of primary infections and/ or nosocomial infections from patients at Kenyatta National Hospital Intensive Care Unit (KNH ICU) (Njoki, 2009).

Nonetheless, since most infections are linked to well-known free pathogens, the role of FLA such as Acanthamoeba spp. and ARMs such as Pseudomonas spp. in disease burden is mostly overlooked (Khan and Siddiqui, 2014). This could be one of the reasons for the escalated rates of nosocomial infections despite stringent infection control measures (Altayyar et al., 2016). This is further complicated by the lack of information on FLA, ARMs and the possible effects of their interactions and the lack of awareness among healthcare personnel in Kenya. The study therefore sought to assess the prevalence of Acanthamoeba sp. and associated Pseudomonas sp. from selected surfaces and equipment in ICU at Kenyatta National Hospital (KNH), the largest teaching and referral hospital in East and Central Africa located in Nairobi, the capital city of Kenya, in order to inform infection control policy.

\section{Methods}

This was a cross-sectional study in which Acanthamoeba spp. and free bacteria were cultured and isolated from swabs collected from selected surfaces and equipment in ICU at $\mathrm{KNH}$, and detection of Pseudomonas sp. genomic DNA within the isolated Acanthamoeba spp. using PCR was done. Surfaces and equipment in the hospital ICU that could potentially act as fomites were identified and swabs collected.

\section{Specimen collection, culture and isolation}

Swabs were aseptically collected from selected surfaces and equipment in duplicate and immediately delivered to the University of Nairobi Medical Microbiology Laboratory. Bacterial cultures were performed on one batch of swabs on Blood Agar (BA) and MacConkey (MAC) agar using the streak plate procedure 
and aerobically incubated at $37^{\circ} \mathrm{C}$ for 18 to 24 hours (Sanders, 2012). Plain plates of BA and MAC were used as negative controls and Pseudomonas sp. ATCC 27853 inoculated on BA and MAC plates were used as positive controls under the same conditions. Bacteria identification was based on colonial morphology, haemolysis on BA, lactose fermentation, Gram stain results and biochemical tests (Bisen et al. 2012).

Acanthamoeba spp. culture and detection of ARMs from the second batch of swabs was done as described by others (Lagier et al. 2015). Acanthamoeba castellani trophozoites (ATCC 30010) were cultured on Non-Nutrient Agar (NNA) media as positive control and to confirm the suitability of NNA for its intended use (Kara et al., 2015). The swabs for use in Acanthamoeba sp. culture were suspended in 2 milliliters $(\mathrm{ml})$ sterile Page saline in $13 \times 100 \mathrm{~mm}$ tubes and centrifuged at 1000 revolution per minute (RPM) for 10 minutes (Fukumoto et al., 2016). The sediments were inoculated on NNA culture plates overlaid with heat-killed Escherichia coli (Jeong and Yu, 2005; Trabelsi et al., 2010; Aç et al., 2013; Ovrutsky et al., 2013; Ghaderifar et al., 2018). Inoculated plates were tightly sealed with parafilm to avoid desiccation and aerobically incubated at $37^{\circ} \mathrm{C}$ (Douesnard-Malo and Daigle, 2011; Muchesa et al., 2014). Acanthamoeba spp. growth was monitored daily for up to 2 weeks (Booton et al. 2010; Ovrutsky et al. 2013; Lorenzo-morales et al. 2015; Marciano-Cabral et al. 2014). To confirm growth of Acanthamoeba spp., a few colonies from the amoeba feeding tracks were suspended in normal saline and observed under a light microscope (Booton et al. 2010; Chomicz et al. 2015; Panda et al. 2015). Acanthamoeba spp. from positive plates were confirmed after staining with Eosin and Methylene Blue stains (El-Sayed and Hikal, 2015). Acanthamoeba trophozoites were identified based on features such as the characteristic active motility, prominent spine-like acanthapodia on the surface of trophozoites, a large food vacuole and a nucleus whereas cysts were identified based on their irregular wrinkled outer layer, a prominent double wall enclosing an ectocyst, a polygonal shaped endocyst and a nucleus (Khan, 2006; Liang et al., 2010; Duarte et al., 2013; Yousuf, Siddiqui and Khan, 2013; Al-Ghamdi, 2016; Gad and Alherrawy, 2016; Behnia et al., 2017; Karakavuk et al., 2017; Vijayakumar, 2018; Wang et al., 2018).

Approximately $1 \mathrm{~cm}^{2}$ pieces of agar were cut from positive plates and sub-cultured on new NNA agar plates overlaid with heat killed Escherichia coli and $100 \mu \mathrm{g} / \mathrm{ml}$ gentamycin to obtain pure cultures of Acanthamoeba spp. (Bleasdale et al., 2009; Ovrutsky et al., 2013; Yousuf, Siddiqui and Khan, 2013; Lorenzo-Morales, Khan and Walochnik, 2015).

\section{Pseudomonas sp. DNA extraction from Acanthamoeba spp. isolates}

Extraction of total Pseudomonas sp. genomic DNA from known positive control of Pseudomonas sp. ATCC 27853 obtained from University of Nairobi Medical Microbiology Laboratory and from Acanthamoeba sp. isolates was done separately as described by others (Paulo 2015; Aljanabi et al. 1997).

PCR detection of Pseudomonas sp. genomic DNA 
Detection of Pseudomonas sp. genomic DNA was done using PCR (Spilker et al., 2004; Paulo, 2015). The primers PA-GS-F (5'- GACGGGTGAGTAATGCCTA-3') and PA-GS-R (5'-CACTGGTGTTCCTTCCTATA-3') were used to amplify 618 base pairs fragment of the Pseudomonas sp. genomic DNA. Agarose gel electrophoresis of the amplified products was run as described by others (Sambrook and Russell, 2006; Kafkas et al., 2012). Pseudomonas sp. ATCC 27853 as positive control bands were used to locate and identify amplified Pseudomonas sp. genomic DNA extracted from Acanthamoeba spp. isolates.

\section{Results}

\section{Acanthamoeba spp.}

A total of 153 swabs were cultured on NNA for the isolation of Acanthamoeba spp. Almost all 143 (93.5\%) of swabs were positive for Acanthamoeba spp. Acanthamoeba spp. (Figs. 1 and 2) growth was positively associated with the swab location; $P=0.008\left(\chi^{2}=71.160 \mathrm{df} 45\right)$. Subsequent sub-cultures to purify Acanthamoeba spp. isolates was done on 96 of the primary Acanthamoeba spp. cultures of which only $22(22.9 \%)$ were successful. There was a considerable drop in the proportion of positive Acanthamoeba spp. subcultures (Table 1). 
Table 1

Acanthamoeba spp. Culture and Subculture

\begin{tabular}{|c|c|c|c|c|}
\hline $\begin{array}{l}\text { Swab } \\
\text { location }\end{array}$ & $\begin{array}{l}\text { No. of } \\
\text { Swabs } \\
\text { cultured }\end{array}$ & $\begin{array}{l}\text { No. of culture plates } \\
\text { with Acanthamoeba } \\
\text { spp. growth }\end{array}$ & $\begin{array}{l}\text { No. of } \\
\text { Acanthamoeba } \\
\text { spp. purification } \\
\text { subcultures }\end{array}$ & $\begin{array}{l}\text { No. of cultures positive } \\
\text { for Acanthamoeba spp. } \\
\text { upon subculture }\end{array}$ \\
\hline Sinks & 21 & $21(100.0 \%)$ & $13(61.9 \%)$ & $6(46.2 \%)$ \\
\hline $\begin{array}{l}\text { ECG* } \\
\text { machine }\end{array}$ & 21 & 21 (100.0\%) & 12 (57.1\%) & 1 (0.08\%) \\
\hline Bed rails & 21 & 20 (95.2\%) & $16(76.2 \%)$ & $1(0.63 \%)$ \\
\hline $\begin{array}{l}\text { Patient } \\
\text { lockers }\end{array}$ & 21 & 19 (90.5\%) & $11(52.4 \%)$ & $1(9.1 \%)$ \\
\hline Ventilators & 16 & 16 (100.0\%) & 11 (68.8\%) & $2(18.2 \%)$ \\
\hline $\begin{array}{l}\text { Suction } \\
\text { machines }\end{array}$ & 13 & $11(84.6 \%)$ & 9 (69.2\%) & $4(44.4 \%)$ \\
\hline Door handles & 9 & $6(66.7 \%)$ & $7(77.8 \%)$ & $1(0.14 \%)$ \\
\hline Floor & 6 & $5(83.3 \%)$ & $3(50.0 \%)$ & $0(0.0 \%)$ \\
\hline Drip stands & 6 & $6(100.0 \%)$ & $3(50.0 \%)$ & $0(0.0 \%)$ \\
\hline $\begin{array}{l}\text { Soap } \\
\text { containers }\end{array}$ & 6 & $6(100.0 \%)$ & $5(83.3 \%)$ & $3(60 \%)$ \\
\hline $\begin{array}{l}\text { Telephone } \\
\text { handles }\end{array}$ & 3 & $3(100.0 \%)$ & $1(33.3 \%)$ & $1(100.0 \%)$ \\
\hline Walls & 2 & $2(100.0 \%)$ & $1(50.0 \%)$ & $0(0.0 \%)$ \\
\hline $\begin{array}{l}\text { Resuscitation } \\
\text { trolleys }\end{array}$ & 2 & $2(100.0 \%)$ & $1(50.0 \%)$ & $0(0.0 \%)$ \\
\hline Nurses desks & 2 & $2(100.0 \%)$ & $0(0.0 \%)$ & - \\
\hline $\begin{array}{l}\text { Central } \\
\text { monitor } \\
\text { screens }\end{array}$ & 2 & $2(100.0 \%)$ & $2(100.0 \%)$ & $1(50 \%)$ \\
\hline Defibrillators & 2 & $1(50.0 \%)$ & $1(50.0 \%)$ & $1(100.0 \%)$ \\
\hline Totals & 153 & $143(93.5 \%)$ & 96 (62.7\%) & $22(22.9 \%)$ \\
\hline \multicolumn{5}{|c|}{ *ECG = Electrocardiography } \\
\hline \multicolumn{5}{|c|}{$\begin{array}{l}\text { Acanthamoeba spp. growth was associated with the swab location; } P=0.008\left(\chi^{2}=71.160 \mathrm{df} 45\right) \text {. All } \\
\text { swabs collected from sinks, ECG machine, telephone handles, drip stands, soap containers, walls, } \\
\text { ventilators, resuscitation trolleys and nurses' desks had } 100 \% \text { growth of Acanthamoeba spp. The } \\
\text { least growth of Acanthamoeba spp. was obtained from defibrillators swabs at } 50 \% \text { followed by door } \\
\text { handles swabs at } 66.7 \% \text {. }\end{array}$} \\
\hline
\end{tabular}


Pseudomonas sp. genomic DNA from isolated Acanthamoeba spp.

Conventional polymerase chain reaction was performed on a total of 22 positive Acanthamoeba spp. subcultures to detect Pseudomonas sp. genomic DNA within Acanthamoeba spp. isolates. Of the 22 PCR tested subcultures, 6 had been obtained from swabs collected from sinks, 4 from suction machines, 3 from soap containers, 2 from ventilators and 1 each from the ECG, door handles, telephone handles, bed rails, patient lockers, central monitors and defibrillators. Pseudomonas sp. genomic DNA within Acanthamoeba spp. isolates was detected from almost half 10 (45.5\%) of the PCR tested Acanthamoeba spp. subcultures. Of the 10 PCR positive subcultures, 4 were from sinks, 2 from suction machines and 1 each from bedrails, ventilators, door handles and soap containers. The proportion of the surfaces and equipment with PCR detected Pseudomonas sp. genomic DNA was 6.5\% $(n=153)$. Nevertheless, there was no association between swab location and detection of Pseudomonas sp. genomic DNA by PCR ( $p=$ $\left.0.590 ; \chi^{2}=13.160 \mathrm{df} 15\right)$. The Gel electrophoresis images for the detection of Pseudomonas sp. genomic DNA after PCR amplification are shown in Fig. 3.

\section{Bacterial cultures}

The second batch of 153 swabs collected from selected surfaces and equipment at KNH ICU was cultured on BA and MAC agar for the isolation and identification of bacteria. Of the 153 cultured swabs $143(82.4 \%)$ swabs had bacterial growth. A total of 168 bacterial isolates were identified of which Staphylococcus aureus was the most prevalent $-68(44.4 \%)$ followed by coagulase negative Staphylococcus - 42 (27.5\%), Klebsiella spp. 19 (12.4\%) and Pseudomonas spp. - 18 (10.7\%). The least isolated bacteria were Escherichia coli and Serattia spp. with 1 (0.7\%) isolate each.

\section{Discussion}

The study, aiming at isolating Acanthamoeba spp. and detecting Pseudomonas sp. genomic DNA within the isolated Acanthamoeba spp. from selected surfaces and equipment was conducted in the ICU at Kenyatta National Hospital. To the best of our knowledge this was the first study on Acanthamoeba spp. and the associated ARMs in Kenya.

Acanthamoeba spp. were detected in $93.5 \%$ of the 153 swabs on various surfaces and equipment. There was an association observed between Acanthamoeba spp. growth and the swab location; $P=0.008\left(\chi^{2}=\right.$ $71.160 \mathrm{df} 45)$. These results are in agreement with the $99.1 \%$ prevalence of Acanthamoeba spp. reported in water matrices samples in Spain (Izquierdo et al., 2013; Montalbano et al., 2015). The prevalence reported in the present study could be attributed to accumulation of bacterial mat and dirt on the surfaces and equipment. A similar explanation has been advanced by others who noted that Acanthamoeba spp. are attracted to areas with abundant bacteria and high organic matter which provide nutrition for the protozoan (Sente et al., 2016; Balczun and Scheid, 2017). In contrast, a study conducted in the Middle East obtained a low prevalence of $34.4 \%$ of Acanthamoeba spp. that was related to frequent destruction of biofilms thus reducing bacteria on which FLA feed (Ghaderifar et al., 2018). 
Pseudomonas sp. genomic DNA was detected from Acanthamoeba spp. isolates using PCR. A total of 96 (62.7\%) primary Acanthamoeba spp. isolates were subcultured of which only 22 (22.9\%) were successful. PCR for the detection of Pseudomonas sp. genomic DNA was performed on the 22 Acanthamoeba spp. positive subcultures. Pseudomonas sp. genomic DNA was detected in $10(45 \%)$ samples. These results are similar to findings of a study detecting bacterial endosymbionts in clinical Acanthamoeba spp. isolates where Pseudomonas spp. was the most prevalent (59.1\%) endosymbiotic bacteria (lovieno et al., 2011).

Invasion of and survival within FLA by bacteria is enhanced by effector proteins secreted by Type III or Type IV secretory systems expressed by majority of amoeba resistant bacteria (ARB). The released effector proteins manipulate FLA defense system in the favour of the ARB. This has been reported in Pseudomonas aeruginosa which expresses Type III secretory system that releases effector proteins capable of lysing FLA (Kara et al., 2015). This could partly explain the drop in the number of positive Acanthamoeba spp. subcultures from primary cultures assuming that effector proteins released by Pseudomonas spp. could have lysed majority of primary Acanthamoeba spp isolates.

The detection of Pseudomonas sp. genomic DNA within Acanthamoeba spp. isolates confirms a potential health risk to patients at KNH ICU should these patients acquire ARM infections. This is because the mechanisms used by ARMs to evade amoebic killing could also be used to evade macrophage killing (Balczun and Scheid, 2017). Also, in the event that drug resistant bacteria coexist with drug susceptible bacteria within the same Acanthamoeba sp. host, the Acanthamoeba sp. could become a hot spot of drug resistant gene transfer which could end up increasing the spread of drug resistant bacteria (Bertelli and Greub, 2012; Fukumoto et al., 2016). The study confirmed the co-existence of Pseudomonas spp. within Acanthamoeba spp in a hospital set up. A study in South Africa that detected ARMs within FLA suggested the latter could act as survival and proliferation niches from where ARMs can be transmitted to immunosuppressed patients in hospitals (Muchesa et al., 2017). Although there was no statistically significant association between swab location and detection of Pseudomonas sp. genomic DNA, the present study confirms that Acanthamoeba spp. are ubiquitous and raises a concern for intensive care unit patients.

Of the 168 bacterial isolates identified in the study, $44.4 \%$ were Staphylococcus aureus, $27.5 \%$ coagulase negative Staphylococcus, $11.3 \%$ Klebsiella spp. and 10.7\% Pseudomonas spp. among others. Majority of these bacteria have been implicated in nosocomial infections and resistance to the commonly used antibiotics. This findings are agreement with those of previous studies on agents of nosocomial infections at KNH ICU where between $12.5 \%$ and $25.8 \%$ prevalence of Pseudomonas aeruginosa have been reported (Ngumi, 2006; Inyama et al., 2011)

In the study, Pseudomonas sp. DNA was detected from Acanthamoeba spp. isolates obtained from 6.5\% of the swabbed surfaces and equipment at KNH ICU. This indicates that, although infection control efforts focused on curbing transmission of the bacterium at KNH ICU have been put in place, Pseudomonas spp. could still be surviving within the ubiquitous protozoa which could reseed the 
environment (Costa et al., 2010). This is important considering that the disinfectants currently used to clean surfaces in many health facilities are not effective against FLA such as Acanthamoeba spp. (Iqbal, Siddiqui and Khan, 2014). Consequently, control measures against the spread of drug resistant pathogenic bacteria could also be implicated especially in hospital setting.

\section{Conclusion}

The findings of this study demonstrate that Acanthamoeba sp., a free-living amoeba proliferates on various important surfaces and equipment in the ICU at KNH despite routine cleaning activities. This is most likely to be happening not only in other units of the hospital but in other hospitals as well. The study also demonstrates that Acanthamoeba spp. in the ICU may harbor and act as protected niche for potentially pathogenic bacteria such as Pseudomonas sp. from where the bacteria are re-introduced in the environment thus frustrating nosocomial infection control efforts. This calls for design and implementation of more rigorous cleaning, disinfection and sterilization strategies that are effective against FLA. Drug resistance in pathogenic bacteria is a major global health challenge and future studies to shed light on the role of Acanthamoeba spp. and other FLA in the spread of the antimicrobial drug resistance are needed.

\section{List Of Abbreviations}

ATCC-American Type Culture Collection

ARMs -Amoeba Resistant Microorganisms

ARB -Amoeba Resistant Bacteria

BA-Blood Agar

Bp -Base pair

${ }^{0} \mathrm{C}$-Degrees Centigrade

DNA -Deoxyribonucleic Acid

ECG -Electrocardiography

FLA -Free Living Amoeba

GAE -Granulomatous Amoebic Encephalitis

ICU -Intensive Care Unit

KNH -Kenyatta National Hospital 
MAC-MacConkey

NNA -Non Nutrient Agar

PCR -Polymerase Chain Reaction

RPM -Revolution Per Minute

Sp -Species

UoN-University of Nairobi

WHO -World Health Organization

\section{Declarations}

Ethical Approval: "This study received ethical approval by Kenyatta National Hospital/ University of Nairobi Ethics and Research Committee (Approval No. P303/06/2017)"

Consent for publication: "Not applicable"

Availability of data and materials: The datasets used and/or analysed during the current study are available from the University of Nairobi repository (http://erepository.uonbi.ac.ke/handle/11295/109429).

Competing interests: "The authors declare that they have no competing interests"

Funding: This study was supported by the Kenyatta National Hospital Research Fund, funding number $\mathrm{KNH} / \mathrm{R} \& \mathrm{P} / 23 \mathrm{G} / 3$.

\section{Authors' contributions:}

ZWM: Principal investigator, study conceptualization, design, data collection and analysis and, manuscript preparation

$\mathrm{MWM}^{1,2}$ : Study design, data analysis and manuscript preparation

$\mathrm{MWM}^{1}$ : Data collection

WG: Data collection

MMM: Study design, data analysis and manuscript preparation

$\mathrm{KN}$ : Study conceptualization, design, data collection and analysis and, manuscript preparation and the Corresponding author

\section{Acknowledgements:}


The authors are grateful for the support and guidance provided by the staff at the Medical Microbiology Department, University of Nairobi and Kenyatta National Hospital Intensive Care Unit, Dr. Dunstan Mukoko for his assistance in data analysis and Mr. Joseph Nduati for his assistance in research funds logistics and partly data collection.

\section{References}

1. Aç, K. et al. (2013) 'Isolation and Identification of Free-Living Amoebae from Tap Water in Sivas, Turkey', 2013.

2. Al-Ghamdi, S. (2016) "' Mechanisms associated with Staphylococcus aureus and Acanthamoeba Interactions, and Therapeutic applications "', (April).

3. Aljanabi, S. M. et al. (1997) 'Universal and rapid salt-extraction of high quality genomic DNA for PCRbased techniques', 25(22), pp. 4692-4693.

4. Altayyar, I. A. et al. (2016) 'Prevalence and Antibiotic Susceptibility Pattern of Pseudomonas aeruginosa Isolated from Hospital Environment in South Libya'.

5. Balczun and Scheid (2017) 'Free-Living Amoebae as Hosts for and Vectors of Intracellular Microorganisms with Public'. doi: 10.3390/v9040065.

6. Barnard, T. G. (2015) 'The prevalence of free-living amoebae in a South African hospital water distribution system', 111(1), pp. 3-5.

7. Behnia, M. et al. (2017) 'Occurrence of acanthamoeba genotypes in wastewater samples in tehran, Iran', Iranian Journal of Parasitology, 12(4), pp. 516-521.

8. Bertelli, C. and Greub, G. (2012) 'Lateral gene exchanges shape the genomes of amoeba-resisting microorganisms', 2(August), pp. 1-15. doi: 10.3389/fcimb.2012.00110.

9. Bisen, P. S., Debnath, M. and Prasad, G. B. K. S. (2012) 'MICROBES: Concepts and Applications', (August 2016).

10. Bleasdale, B. et al. (2009) 'The Salmonella pathogenicity island 2-encoded type III secretion system is essential for the survival of Salmonella enterica serovar typhimurium in free-living amoebae', Applied and Environmental Microbiology, 75(6), pp. 1793-1795. doi: 10.1128/AEM.02033-08.

11. Booton, G. C. et al. (2010) 'Genotypic Identification of Acanthamoeba sp. Isolates Associated with with an Outbreak of Acanthamoeba keratitis (AK) Gregory', 28(6), pp. 673-676. doi: 10.1097/ICO.0b013e31819342a7.Genotypic.

12. Cervero-Aragó, S. et al. (2015) 'Effect of common drinking water disinfectants, chlorine and heat, on free Legionella and amoebae-associated Legionella', PLOS ONE, 10(8), pp. 1-18. doi: 10.1371/journal.pone.0134726.

13. Chappell, C. L. et al. (2001) 'Standardized Method of Measuring Acanthamoeba Antibodies in Sera from Healthy Human Subjects', 8(4), pp. 724-730. doi: 10.1128/CDLI.8.4.724.

14. Chomicz, L. et al. (2015) 'Emerging Threats for Human Health in Poland: Pathogenic Isolates from Drug Resistant Acanthamoeba Keratitis Monitored in terms of Their in Vitro Dynamics and 
Temperature Adaptability', BioMed Research International. Hindawi Publishing Corporation, 2015. doi: $10.1155 / 2015 / 231285$.

15. Chow, F. C. and Glaser, C. A. (2014) 'Emerging and Reemerging Neurologic Infections', The Neurohospitalist, 4(4), pp. 173-184. doi: 10.1177/1941874414540685.

16. Clarke, B. et al. (2012) 'Advances in the diagnosis and treatment of acanthamoeba keratitis', Journal of Ophthalmology, 2012. doi: 10.1155/2012/484892.

17. Costa, A. O. et al. (2010) 'Characterization of acanthamoeba isolates from dust of a public hospital in curitiba, paran??, Brazil', Journal of Eukaryotic Microbiology, 57(1), pp. 70-75. doi: 10.1111/j.1550-7408.2009.00453.x.

18. Davane, M. et al. (2014) 'Pseudomonas aeruginosa from hospital environment', 4(1), pp. 42-43. doi: 10.5799/ahinjs.02.2014.01.0124.

19. Dendana, F. et al. (2008) 'Free-living amoebae (FLA): detection, morphological and molecular identification of Acanthamoeba genus in the hydraulic system of an haemodialysis unit in Tunisia.', Parasite (Paris, France), 15(2), pp. 137-42. doi: 10.1051/parasite/2008152137.

20. Douesnard-Malo, F. and Daigle, F. (2011) 'Increased persistence of Salmonella enterica Serovar typhi in the presence of Acanthamoeba castellanii', Applied and Environmental Microbiology, 77(21), pp. 7640-7646. doi: 10.1128/AEM.00699-11.

21. Duarte, J. L. et al. (2013) 'Morphological, genotypic, and physiological characterization of Acanthamoeba isolates from keratitis patients and the domestic environment in Vitoria, Espírito Santo, Brazil', Experimental Parasitology. Academic Press, 135(1), pp. 9-14. doi: 10.1016/J.EXPPARA.2013.05.013.

22. El-Sayed, N. M. and Hikal, W. M. (2015) 'Several staining techniques to enhance the visibility of Acanthamoeba cysts', Parasitology Research, 114(3), pp. 823-830. doi: 10.1007/s00436-014-41904.

23. Essa, M. et al. (2016) 'Allovahlkampfia spelaea Causing Keratitis in Humans', pp. 1-10. doi: 10.1371/journal.pntd.0004841.

24. Fabres, L. F. et al. (2016) 'Marine amoebae with cytoplasmic and perinuclear symbionts deeply branching in the Gammaproteobacteria.', Acta Parasitologica. Nature Publishing Group, 61(2), p. 13381. doi: $10.1038 /$ srep13381.

25. Fukumoto, T. et al. (2016) 'Acanthamoeba containing endosymbiotic chlamydia isolated from hospital environments and its potential role in inflammatory exacerbation', BMC Microbiology. BMC Microbiology, pp. 1-8. doi: 10.1186/s12866-016-0906-1.

26. Gad, M. A. and Al-herrawy, A. Z. (2016) 'Real Time PCR Detection of Acanthamoeba Species in the Egyptian Aquatic Environment', 8(11), pp. 1510-1515.

27. Ghaderifar, S. et al. (2018) 'Isolation and identification of Acanthamoeba from pond water of parks in a tropical and subtropical region in the Middle East, and its relation with physicochemical parameters'. BMC Microbiology, pp. 4-9. 
28. Gimenez, G. et al. (2011) 'Insight into cross-talk between intra-amoebal pathogens', BMC Genomics. BioMed Central Ltd, 12(1), p. 542. doi: 10.1186/1471-2164-12-542.

29. Greub, G. and Raoult, D. (2004) 'Microorganisms Resistant to Free-Living Amoebae', Clinical Microbiology Reviews, 17(2), pp. 413-433. doi: 10.1128/CMR.17.2.413-433.2004.

30. Gryseels, S. et al. (2012) 'Amoebae as Potential Environmental Hosts for Mycobacterium ulcerans and Other Mycobacteria, but Doubtful Actors in Buruli Ulcer Epidemiology', PLoS Neglected Tropical Diseases, 6(8). doi: 10.1371/journal.pntd.0001764.

31. Guimaraes, A. J. et al. (2016) 'Acanthamoeba spp. as a universal host for pathogenic microorganisms: One bridge from environment to host virulence', Microbiological Research. doi: 10.1016/j.micres.2016.08.001.

32. Horn, M. (2001) 'Molecular Ecology of Free-living Amoebae and Their Bacterial Endosymbionts: Diversity and Interactions', (June).

33. Hsueh, T. Y. and Gibson, K. E. (2015) 'Interactions between human norovirus surrogates and Acanthamoeba spp', Applied and Environmental Microbiology, 81(12), pp. 4005-4013. doi: 10.1128/AEM.00649-15.

34. Inyama, H. et al. (2011) 'The incidence of nosocomial urinary trat infection:Kenyatta National Hospital -Intensive care unit', Baraton University Interdisciplinary Research Journal, 1(2), pp. 12-21.

35. Iovieno, A. et al. (2011) 'Detection Of Bacterial Endosymbionts In Clinical Acanthamoeba Isolates', 117(November 2008), pp. 445-452. doi: 10.1016/j.ophtha.2009.08.033.Detection.

36. Iqbal, J., Siddiqui, R. and Khan, N. A. (2014) 'Acanthamoeba and bacteria produce antimicrobials to target their counterpart', Parasites \& Vectors. Parasites \& Vectors, 7(1), pp. 1-6. doi: 10.1186/17563305-7-56.

37. Izquierdo, F. et al. (2013) 'A year long study of the presence of free living amoeba in Spain', pp. 1-7. doi: 10.1016/j.watres.2013.09.065.

38. Jeong, H. J. and Yu, H. S. (2005) 'The role of domestic tap water in Acanthamoeba contamination in contact lens storage cases in Korea.', The Korean journal of parasitology, 43(2), pp. 47-50. doi: 10.3347/kjp.2005.43.2.47.

39. Kafkas, G. et al. (2012) 'Principles of Nucleic Acid Separation by Agarose Gel Electrophoresis Principles of Nucleic Acid Separation by Agarose Gel Electrophoresis', (January 2016). doi: $10.5772 / 38654$.

40. Kara, M. A. et al. (2015) 'Growth and Survival of Mesorhizobium loti Inside Acanthamoeba Enhanced Its Ability to Develop More Nodules on Lotus corniculatus', pp. 566-575. doi: 10.1007/s00248-0150587-6.

41. Karakavuk, M. et al. (2017) 'First time identification of Acanthamoeba genotypes in the cornea samples of wild birds; Is Acanthamoeba keratitis making the predatory birds a target?', Experimental Parasitology, 183(May), pp. 137-142. doi: 10.1016/j.exppara.2017.08.007.

42. Khan, N. A. (2003) 'Pathogenesis of Acanthamoeba infections', Microbial Pathogenesis, 34(6), pp. 277-285. doi: 10.1016/S0882-4010(03)00061-5. 
43. Khan, N. A. (2006) 'Acanthamoeba: biology and increasing importance in human health', 30, pp. 564-595. doi: 10.1111/j.1574-6976.2006.00023.x.

44. Khan, N. A. and Siddiqui, R. (2014) 'War on terror cells: killing the host that harbours " superbugs " is an infection control strategy in our fight against infectious diseases'. doi:

$10.1179 / 2047773213 Y .0000000125$.

45. Lagier, J. et al. (2015) 'Microbiology SUMMARY', 28(1), pp. 208-236. doi: 10.1128/CMR.00110-14.

46. Lakhundi, S., Siddiqui, R. and Khan, N. (2015) 'Cellulose degradation: a therapeutic strategy in the improved treatment of Acanthamoeba infections.', Parasites \& vectors, 8(1), p. 23. doi: 10.1186/s13071-015-0642-7.

47. Lamrabet, O. et al. (2012) 'The genealogic tree of mycobacteria reveals a long-standing sympatric life into free-living protozoa.', PloS one, 7(4), p. e34754. doi: 10.1371/journal.pone.0034754.

48. Lass, A. et al. (2014) 'The first genotype determination of Acanthamoeba potential threat to human health, isolated from natural water reservoirs in Poland', Parasitology Research, 113(7), pp. 26932699. doi: 10.1007/s00436-014-3925-6.

49. Liang, S. Y. et al. (2010) 'Isolation and identification of Acanthamoeba species related to amoebic encephalitis and nonpathogenic free-living amoeba species from the rice field', Journal of Applied Microbiology, 109(4), pp. 1422-1429. doi: 10.1111/j.1365-2672.2010.04779.x.

50. Lim, S. and Webb, S. A. R. (2005) 'Nosocomial bacterial infections in Intensive Care Units . I: Organisms and mechanisms of antibiotic resistance', pp. 887-902. doi: 10.1111/j.13652044.2005.04220.x.

51. Lorenzo-morales, J., Khan, N. A. and Walochnik, J. (2015) 'An update on Acanthamoeba keratitis: diagnosis, pathogenesis and treatment'. doi: 10.1051/parasite/2015010.

52. Lorenzo-Morales, J., Khan, N. A. and Walochnik, J. (2015) ' An update on Acanthamoeba keratitis: diagnosis, pathogenesis and treatment ', Parasite, 22(April), p. 10. doi: 10.1051/parasite/2015010.

53. Marciano-Cabral, F. et al. (2014) 'Improved method for the detection and quantification of naegleria fowleri in water and sediment using immunomagnetic separation and real-time PCR', BMC genomics, 27(1), pp. 254-259. doi: 10.1017/СВ09781107415324.004.

54. Marciano-Cabral, F. and Cabral, G. (2003a) 'Acanthamoeba spp. as agents of disease in humans.', Clinical microbiology reviews, 16(2), pp. 273-307. doi: 10.1128/CMR.16.2.273.

55. Marciano-Cabral, F. and Cabral, G. (2003b) 'Acanthamoeba spp. as agents of disease in humans', Clinical Microbiology Reviews, 16(2), pp. 273-307. doi: 10.1128/CMR.16.2.273-307.2003.

56. Mattana et al. (2016) 'Acanthamoeba castellanii Genotype T4 Stimulates the Production of Interleukin-10 as Well as Proinflammatory Cytokines in THP-1 Cells', 84(10), pp. 2953-2962. doi: 10.1128/IAl.00345-16.Editor.

57. Montalbano, M. et al. (2015) 'Isolation and Molecular Characterization of Free-Living Amoebae from Different Water Sources in Italy', 46, pp. 3417-3427. doi: 10.3390/ijerph120403417. 
58. Moon, E. et al. (2008) 'Characterization of a Serine Proteinase Mediating Encystation', 7(9), pp. 1513-1517. doi: 10.1128/EC.00068-08.

59. Muchesa, P. et al. (2014) 'Detection of free-living amoebae using amoebal enrichment in a wastewater treatment plant of Gauteng Province, South Africa.', BioMed research international. Hindawi Publishing Corporation, 2014, p. 575297. doi: 10.1155/2014/575297.

60. Muchesa, P. et al. (2017) 'Coexistence of free-living amoebae and bacteria in selected South African hospital water distribution systems', Parasitology Research, 116(1), pp. 155-165. doi: 10.1007/s00436-016-5271-3.

61. Ngumi, Z. W. W. (2006) 'Nosocomial Infections at Kenyatta National Hospital Intensive-Care Unit in Nairobi , Kenya', 212(suppl 1), pp. 4-7. doi: 10.1159/000089192.

62. Njoki, K. R. (2009) 'Risk Factors and Treatment Patterns of Ventilator Associated Pneumonia in Intensive Care Patients at Kenyatta National Hospital', (November).

63. Ovrutsky, A. R. et al. (2013) 'Cooccurrence of free-living amoebae and nontuberculous mycobacteria in hospital water networks, and preferential growth of mycobacterium avium in Acanthamoeba lenticulata', Applied and Environmental Microbiology, 79(10), pp. 3185-3192. doi: 10.1128/AEM.03823-12.

64. Panda, A. et al. (2015) 'Prevalence of Naegleria fowleri in Environmental Samples from Northern Part of India', pp. 1-14. doi: 10.1371/journal.pone.0137736.

65. Paulo, S. (2015) 'BRIEF COMMUNICATION IDENTIFICATION OF Pseudomonas spp . AS AMOEBARESISTANT MICROORGANISMS IN ISOLATES OF Acanthamoeba', 57(1), pp. 81-83.

66. da Rocha-Azevedo, B., Tanowitz, H. B. and Marciano-Cabral, F. (2009) 'Diagnosis of infections caused by pathogenic free-living amoebae.', Interdisciplinary perspectives on infectious diseases, 2009, p. 251406. doi: 10.1155/2009/251406.

67. Rubenina, l. et al. (2017) 'Relationships between free-living amoeba and their intracellular bacteria', Proceedings of the Latvian Academy of Sciences, Section B: Natural, Exact, and Applied Sciences, 71(4), pp. 259-265. doi: 10.1515/prolas-2017-0044.

68. Saeed, A. et al. (2012) 'Temperature depended role of Shigella flexneri invasion plasmid on the interaction with Acanthamoeba castellanii', International Journal of Microbiology, 2012. doi: 10.1155/2012/917031.

69. Sambrook, J. and Russell, D. W. (2006) 'Agarose Gel Electrophoresis', pp. 3-6. doi: 10.1101/pdb.prot4020.

70. Sanders, E. R. (2012) 'Aseptic Laboratory Techniques: Plating Methods 2 . Streak Plate Procedure: Isolation of Bacterial Colonies Using the Quadrant Method', (May), pp. 1-18. doi: 10.3791/3064.

71. Sente, C. et al. (2016) 'Occurrence and genetic characterisation of Acanthamoeba spp. from environmental and domestic water sources in Queen Elizabeth Protected Area, Uganda.', Parasites \& vectors. Parasites \& Vectors, 9, p. 127. doi: 10.1186/s13071-016-1411-y.

72. Shokri, A. et al. (2016) 'Isolation and Genotyping of Acanthamoeba spp . as Neglected Parasites in North of Iran', 54(4), pp. 447-453. 
73. Siddiqui, R. and Khan, N. A. (2012) 'Biology and pathogenesis of Acanthamoeba', Parasites \& Vectors. BioMed Central Ltd, 5(1), p. 6. doi: 10.1186/1756-3305-5-6.

74. Siripanth, C. and Med, T. (2005) 'Amphizoic Amoebae: Pathogenic Free-living Protozoa; Review of the Literature and Review of Cases in Thailand', 88(5), pp. 701-707.

75. Souza, D. De (2018) 'Extracellular vesicles and vesicle-free secretome of the protozoa Acanthamoeba castellanii under homeostasis and nutritional stress and their damaging potential to host cells', 9(1), pp. 818-836.

76. Spilker, T. et al. (2004) 'PCR-Based Assay for Differentiation of Pseudomonas aeruginosa from Other Pseudomonas Species Recovered from Cystic Fibrosis Patients', 42(5), pp. 2074-2079. doi: 10.1128/JCM.42.5.2074.

77. Szénási, Z. et al. (1998) 'Isolation, identification and increasing importance of "free-living" amoebae causing human disease', Journal of Medical Microbiology, 47(1), pp. 5-16. doi: 10.1099/0022261547-1-5.

78. Taravaud, A., Loiseau, P. M. and Pomel, S. (2017) 'In vitro evaluation of antimicrobial agents on Acanthamoeba sp. and evidence of a natural resilience to amphotericin B', International Journal for Parasitology: Drugs and Drug Resistance, 7(3), pp. 328-336. doi: 10.1016/j.ijpddr.2017.09.002.

79. Teixeira, L. H. et al. (2009) 'Prevalence of Potentially Pathogenic Free-Living Amoebae from Acanthamoeba and Naegleria Genera in Non-Hospital , Public , Internal Environments from the City of Santos , Brazil', 13, pp. 395-397.

80. Trabelsi, H. et al. (2010) 'Free-Living Amoebae (FLA) Morphological and Molecular Identification of Acanthamoeba in Dental Unit Water', Parasite, 17, pp. 67-70. doi: 10.1051/parasite/2010171067.

81. Vijayakumar, R. (2018) 'Isolation, identification of pathogenic Acanthamoeba from drinking and recreational water sources in Saudi Arabia', Journal of Advanced Veterinary and Animal Research, 5(4), p. 439. doi: 10.5455/javar.2018.e296.

82. Wang, M. et al. (2018) 'Identification and genotypic characterization of potentially pathogenic acanthamoeba isolated from tap water in Wuxi, China', Korean Journal of Parasitology, 56(6), pp. 615-618. doi: 10.3347/kjp.2018.56.6.615.

83. Yousuf, F. A., Siddiqui, R. and Khan, N. A. (2013) 'Acanthamoeba castellanii of the T4 genotype is a potential environmental host for Enterobacter aerogenes and Aeromonas hydrophila', Parasites and Vectors. Parasites \& Vectors, 6(1), p. 1. doi: 10.1186/1756-3305-6-169.

\section{Figures}




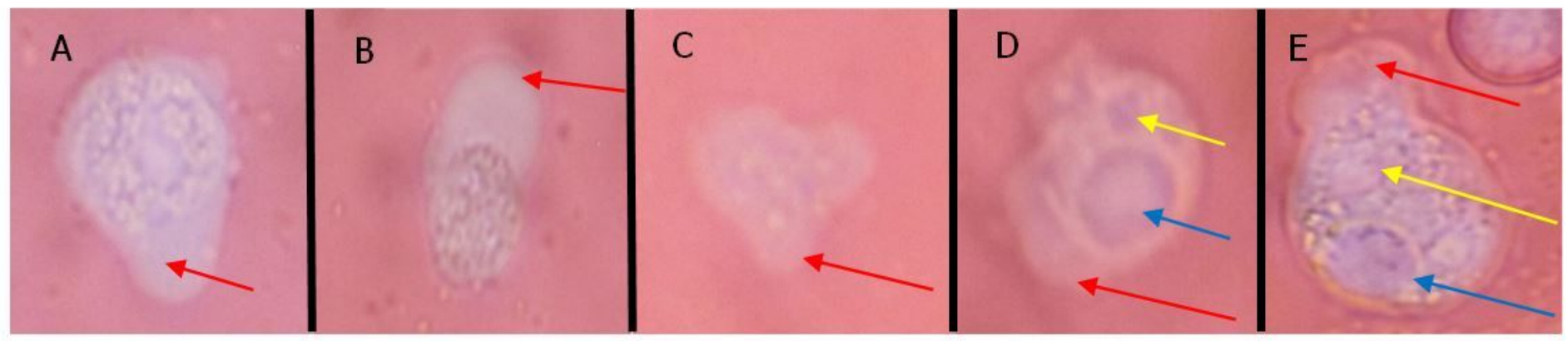

\section{Figure 1}

Eosin Stained Acanthamoeba Trophozoites Displaying Prominent Identification Features as Observed Under Light Microscope. (A to E) Trophozoites of Acanthamoeba spp. with acanthapodia (red arrow) used for locomotion and food uptake; ( $D$ and $E$ ) Trophozoites with a large food vacuole (blue arrow) and a nucleus (yellow arrow)

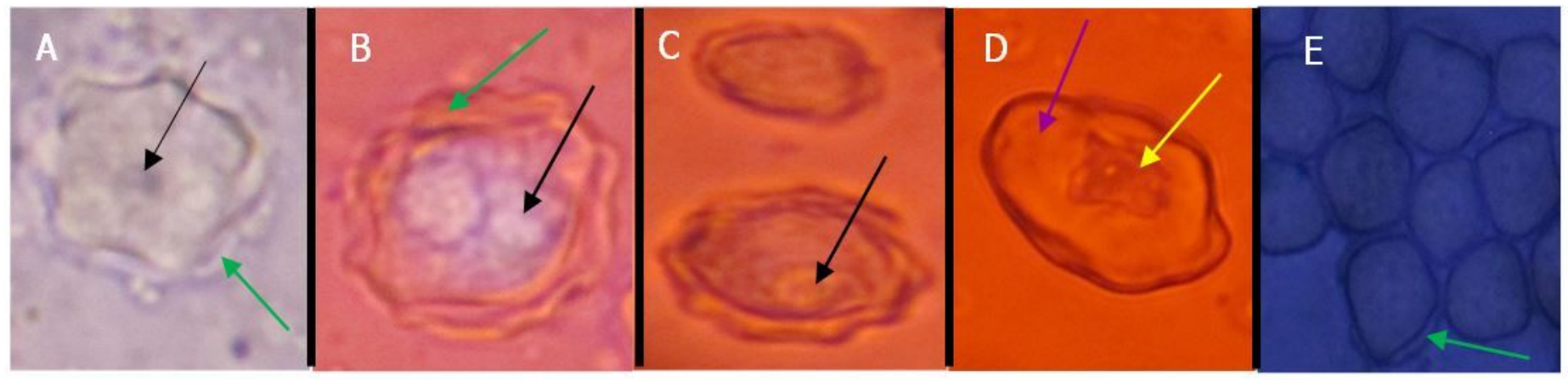

\section{Figure 2}

Acanthamoeba Cysts Showing Distinguishing Features on Different Staining Techniques as Observed Under Light Microscope. (A) Cyst on wet saline mount; (B, C and D) Eosin stained cysts and (E) Methylene blue stained cysts. Irregular wrinkled outer layer (green arrows); double wall enclosing the Ectocyst (purple arrow) and the inner Endocyst polygonal in shape (yellow arrow) and Nucleus (black arrow). 


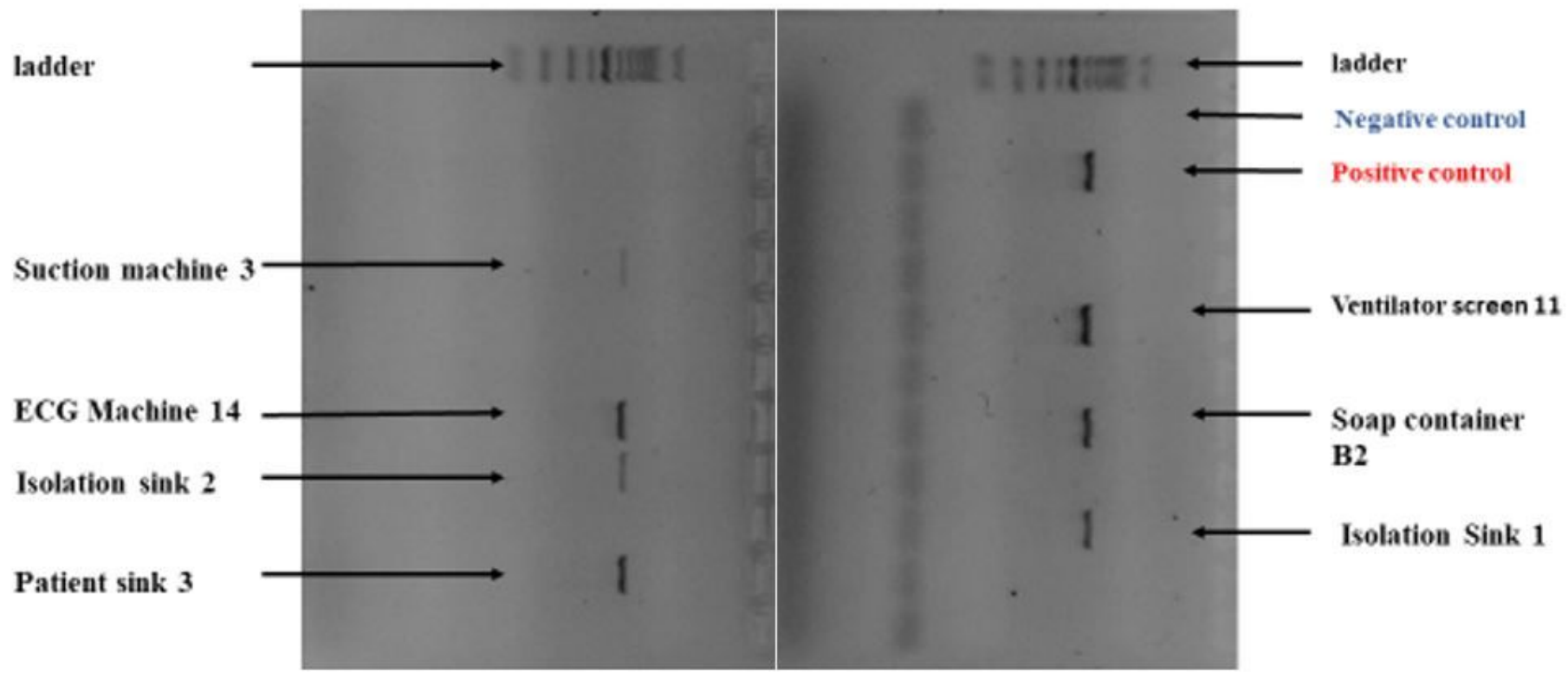

\section{Figure 3}

Gel Electrophoresis Image for Pseudomonas sp. Genomic DNA Detection by PCR Molecular weight marker QIAGEN GelPilot 100bp plus ladder (100 -1500bp) (cat.no.239035) was used to locate and identify amplified Pseudomonas sp. genomic DNA (618 base pairs) extracted from Acanthamoeba spp. isolates. Pseudomonas aeruginosa (ATCC 27853) was used as a positive control 